\title{
Improving aboveground biomass estimates by taking into account density variations between tree components
}

\author{
Antoine Billard $^{1}$ (D) $\cdot$ Rodolphe Bauer $^{1} \cdot$ Frédéric Mothe $^{1} \cdot$ Mathieu Jonard $^{2} \cdot$ Francis Colin $^{1} \cdot$ Fleur Longuetaud $^{1}$
}

Received: 21 April 2020 / Accepted: 8 September 2020 / Published online: 26 October 2020

(C) INRAE and Springer-Verlag France SAS, part of Springer Nature 2020

\begin{abstract}
- Key message Strong density differences were observed between stem wood at $1.30 \mathrm{~m}$ and other tree components (stem wood, stem bark, knots, branch stumps and branches). The difference, up to $40 \%$ depending on the component, should be taken into account when estimating the biomass available for industrial uses, mainly fuelwood and wood for chemistry. - Context Basic density is a major variable in the calculation of tree biomass. However, it is usually measured on stem wood only and at breast height.

- Aims The objectives of this study were to compare basic density of stem wood at $1.30 \mathrm{~m}$ with other tree components and assess the impact of differences on biomass.

- Methods Three softwood species were studied: Abies alba Mill., Picea abies (L.) H. Karst., Pseudotsuga menziesii (Mirb.) Franco. X-Ray computed tomography was used to measure density.

- Results Large differences were observed between components. Basic density of components was little influenced by tree size and stand density. Overall, bark, knot and branch biomasses were highly underestimated by using basic density measured at $1.30 \mathrm{~m}$.

- Conclusion Using available wood density databases mainly based on breast height measurements would lead to important biases (up to more than $40 \%$ ) on biomass estimates for some tree components. Further work is necessary to complete available databases.
\end{abstract}

Keywords Wood specific gravity $\cdot$ Bark $\cdot$ Knots $\cdot$ Branches $\cdot$ Softwoods

\section{Handling Editor: Leo Liu}

Contribution of the co-authors Antoine BILLARD: collected the data, performed the data analysis, wrote the original draft of this paper and was the main writer.

Rodolphe BAUER: helped with the data collection and the validation of the knot volume measurements and contributed to the review and editing.

Frédéric MOTHE: designed the experiment, helped with the data collection and data analysis and contributed to the writing.

Mathieu JONARD: helped with the data analysis and contributed to the discussion, review and editing.

Francis COLIN: participated to the funding acquisition, supervised the work, designed the experiment, coordinated the ExtraFor_Est project, helped with the data collection and contributed to the discussion, review and editing.

Fleur LONGUETAUD: participated to the funding acquisition, supervised the work, designed the experiment, helped with data collection and data analysis, and contributed to the writing.

Antoine Billard antoine.billard@inrae.fr

Extended author information available on the last page of the article.

\section{Introduction}

This work focuses on the estimation of tree aboveground woody biomass, by detailing the different tree components, on the basis of volume data that are widely available from national forest inventories. Such an approach based on volume and a conversion factor, here the density of the tree component, is referred to as an indirect approach (Somogyi et al. 2007; Longuetaud et al. 2013). As opposed to direct approaches based on equations directly giving the biomass but that are less representative at large-scale areas because they are generally based on local studies (Somogyi et al. 2007), this indirect volume $\times$ density approach has the advantage of using the available volume data from national forest inventories that are generally based on sound statistical sampling and to provide at the same time volume and biomass that are both of interest for several industrial uses. Vashum and Jayakumar (2012) provide a review of the existing methods for aboveground biomass estimation, distinguishing direct and indirect approaches. By comparing 
both approaches, Gómez-García et al. (2015) have shown that the volume $\times$ density approach led to less error than a direct method based on biomass equations.

Moreover, with the development of the LiDAR technology for forest inventories, it becomes necessary to provide species-specific density values for each component. It is important that the density values used are reliable and representative of the forest resource (Fearnside 1997; Sagang et al. 2018).

In order to deal simultaneously with the issues of carbon accounting and resource management for the production of products and energy, it is necessary to know the volume and biomass of the different tree components. It is relatively classical to estimate the biomass per tree component based on biomass equations (e.g., Antonio et al. 2007) but not with a volume $x$ density approach with in addition density depending on the component.

More precisely, to convert the volume of standing trees into dry biomass, basic density $(B D)$ has to be used. $B D$ is the ratio of oven-dry weight to green volume.

Accurate and unbiased estimate of biomass is necessary. It is for example usual to estimate carbon sequestration in forests directly from total tree biomass (IPCC 2006; Zhu et al. 2018). The removal of nutrients associated with harvesting is also usually calculated from biomass and average nutrient concentrations (Rothpfeffer and Karltun 2007). In the context of sustainable development, the use of renewable resources has to be optimized. For instance, recent works confirmed that bark and knots contain an important quantity of extractives (Brennan et al. 2020). In particular, knots are a source of lignans (Holmbom et al. 2003) that can be used in cosmetics, medicine and food industries. In order to evaluate the opportunity to develop a wood chemistry industry based on industrial by-products recovery, it is necessary to estimate correctly the amount of biomass available for these novel uses.

However, the biomass of some tree components, especially knots, cannot be assessed correctly until now due to a lack of accurate volume and density data. This particular tree component is also not considered in the direct approaches based on biomass equations because it is not easily measurable. For a given species, the mean density of the different tree components is often poorly known. Indeed, most density measurements reported in the literature were done on knot-free stem wood, generally by sampling a single stem wood core at breast height. Moreover, the measurements were usually carried out on a quite limited number of trees per species and the methods used for density measurements are often questionable (Williamson and Wiemann 2010).
Several recent studies have proved that it is important to consider the variations of wood density within tree to correctly estimate biomass (Repola 2006; Nogueira et al. 2008; Wiemann and Williamson 2013; 2014; Wassenberg et al. 2015; Bastin et al. 2015). Nevertheless, studies focusing on the density of tree components other than the stem wood at breast height are relatively rare.

$B D$ values are provided for stem wood and bark of a lot of North American species by Miles and Smith (2009). Results were highly species-dependent, but, contrary to popular belief, it can be observed that bark was denser than stem wood for most softwood species.

Density of knots was studied by relatively few authors (Wegelius 1940; Boutelje 1966; Hakkila 1971; Lehtonen 1978; Gartner 1995). Knots are generally denser than stem wood for softwood species.

The most studied component are the branches. Several authors found that density of branches was higher than density of stem wood for temperate softwood species (Fegel 1941; Wegelius 1940; McKimmy and Ching 1968; Hakkila 1971; Lehtonen 1978; Gryc et al. 2011; Dibdiakova and Vadla 2012).

In this study, $B D$ of five tree components (stem wood, stem bark, knots, branch stumps and branches) was investigated for three softwood species: Abies alba Mill., Picea abies (L.) H. Karst., and Pseudotsuga menziesii (Mirb.) Franco. Trees were sampled in two contrasted thinning intensity plots. The main objectives were to provide $B D$ values for each tree component for these three species and then to use these values to estimate the biomass of each component and total aboveground biomass. This work with a volume $\times$ density approach with $B D$ values measured for five tree components was never done before. A comparison with the use of a single $B D$ value measured at breast height was done. One of the originalities of this work is to consider the knot and branch stump components with the underlying objective of estimating the resource in extractives. Another originality of this work is the accurate method of measurement based on the use of X-rays.

We will verify that, as in the literature, the $B D$ of knots, branches and bark is higher than that of the stem wood.

In this context, two research hypotheses based on our analysis of the literature were investigated:

$\mathrm{H} 1$ : There is an impact of stand density on the $B D$ of the components. Trees growing in low density stands grow faster and have components with lower $B D$.

$\mathrm{H} 2$ : Taking into account the variation of $B D$ between tree components has an impact on the biomass estimates (tree component and total). 


\section{Materials and methods}

\subsection{Study sites and sampling design}

For each tree species, trees were sampled in a thinning trial managed by the national forest service (ONF): SaintPrix in the East of France for A. alba, Mas-Dorier in the centre of France for P. abies and Mélagues in the South of France for Ps. menziesii. In these forests, contrasted thinning intensities were tested and trees were monitored from the plantation (for Ps. menziesii and P. abies) or natural regeneration (for $A$. alba). Site characteristics are presented in Table 1.

Eight trees were sampled for each species: Four trees in the control plot with no thinning (only natural mortality) and four trees in a heavily thinned plot. We looked at all the tree diameters in the plot. We have divided them evenly into four diameter classes. Then, we chose one tree by diameter class directly on the field. Breast height $(1.30 \mathrm{~m})$ was marked on each standing tree before measuring the circumference that was converted to over-bark diameter at breast height (DBH).

The trees were cut in February 2018. After felling the trees, the total height and the height to the crown base (i.e., the lowest whorl with at least three-fourths of living branches) were measured. Since A. alba trees originated from a natural regeneration, stump discs were sampled to measure tree age.

Main tree characteristics are presented in Table 2.

\subsection{Collection of samples}

Samples were collected for each tree within each tree component (stem wood, bark, knots and branches) for density measurements. Three sets of samples were collected (Fig. 1):

- Samples (A): For measuring the density of stem wood and bark within the stem, 15 discs were sampled along the stem, avoiding knots. The three first discs were taken at fixed heights: $0.30,0.80$ and $1.30 \mathrm{~m}$. The 12 remaining discs were regularly distributed along the stem.

- Samples (B): Seven short logs with whorl branches and related knots were sampled along the stem. Five logs were sampled above crown base to account for knots connected to living branches and two logs below crown base to account for knots connected to dead branches.

- Samples (C): Branches were selected into three size classes based on the diameter at their insertion (insertion diameter): $0-4 \mathrm{~cm}, 4-7 \mathrm{~cm}$ and more than $7 \mathrm{~cm}$. Branches were sampled in each size class but more intensively in larger branch classes, considering that large branches are more likely to be collected for

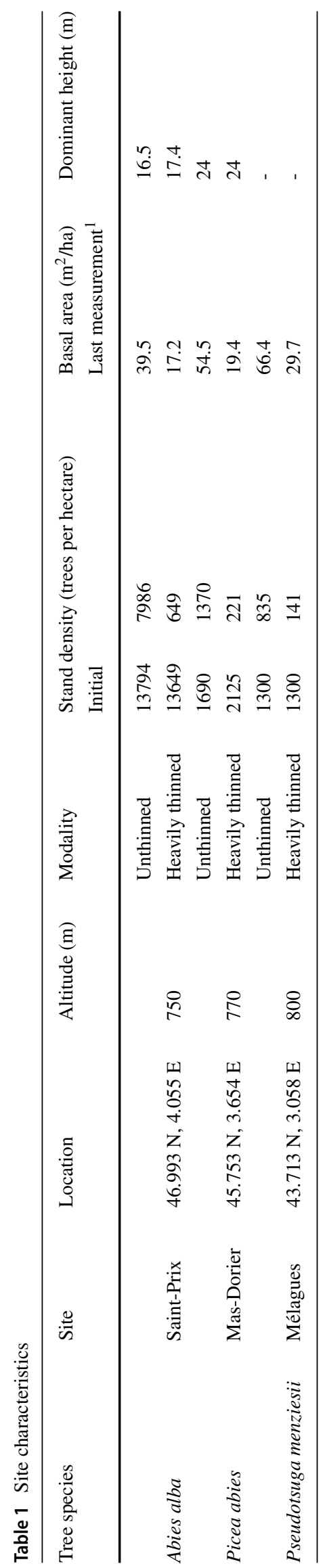

INRAC פ Springer 
Table 2 Characteristics of sampled trees

\begin{tabular}{|c|c|c|c|c|c|c|}
\hline \multirow{2}{*}{$\begin{array}{l}\text { Tree species } \\
\text { Thinning modality }\end{array}$} & \multicolumn{2}{|c|}{ Age range (years) } & \multicolumn{2}{|c|}{ DBH range $(\mathrm{cm})$} & \multicolumn{2}{|c|}{ Height range (m) } \\
\hline & Unthinned & Heavily thinned & Unthinned & Heavily thinned & Unthinned & Heavily thinned \\
\hline Abies alba & $44-57$ & $43-48$ & $10.3-28$ & $19.6-41.2$ & $13.6-22.4$ & $17-21.4$ \\
\hline Picea abies & 53 & 53 & $22.3-40.9$ & $33.7-44$ & $22-30.6$ & $25-29.5$ \\
\hline Pseudotsuga menziesii & 48 & 48 & $23.3-47.4$ & $46.5-65.6$ & $27.2-31.8$ & $26.5-34.1$ \\
\hline
\end{tabular}

industrial applications. As far as possible, 10 branches per tree were selected for the highest available class and five branches for each other classes, by distributing selected branches as regularly as possible all along the crown. For each selected branch, one sample segment was taken at the insertion of the branch and one in each size class along the branch (Fig.1).

\subsection{Wood density measurement}

X-Ray-based methods have been developed for a long time to measure wood density (Polge 1966). Among them, Xray computed tomography (CT) is a non-destructive and fast method (although expensive) able to provide accurate 3D maps of wood density (Longuetaud et al. 2016). CT scanning was applied to measure wood density, i.e., the ratio mass/volume, at different moisture contents (Wei et al. 2011). The oven-dry density $D_{0}$ (i.e., the ovendry mass/oven-dry volume ratio) is obtained by drying the samples at $103{ }^{\circ} \mathrm{C}$ until a constant weight is reached. The method developed by Longuetaud et al. (2016) makes it possible to compute also $B D$ (i.e., the ratio oven-dry mass/green volume) from CT scans at both green and ovendried states. This is especially useful for carbon or biomass accounting since the product of $B D$ by green volume (as it is usually measured by national forest inventories) gives the dry biomass.

In this study, all images were calibrated by using the method described in Freyburger et al. (2009) that was implemented in a specific plug-in called "CalDenQB" for the image analysis software ImageJ (Schneider et al. 2012). We assumed that this calibration works for bark.

The stem discs (A) were scanned twice (green and oven-dried states). The CT images were analysed by using the "sectorization" method described by Longuetaud et al. (2016) to compute both $D_{0}$ and $B D$ for each disc. The disc sectors including knots, despite the care taken in the field to avoid knots in these samples (A), were removed

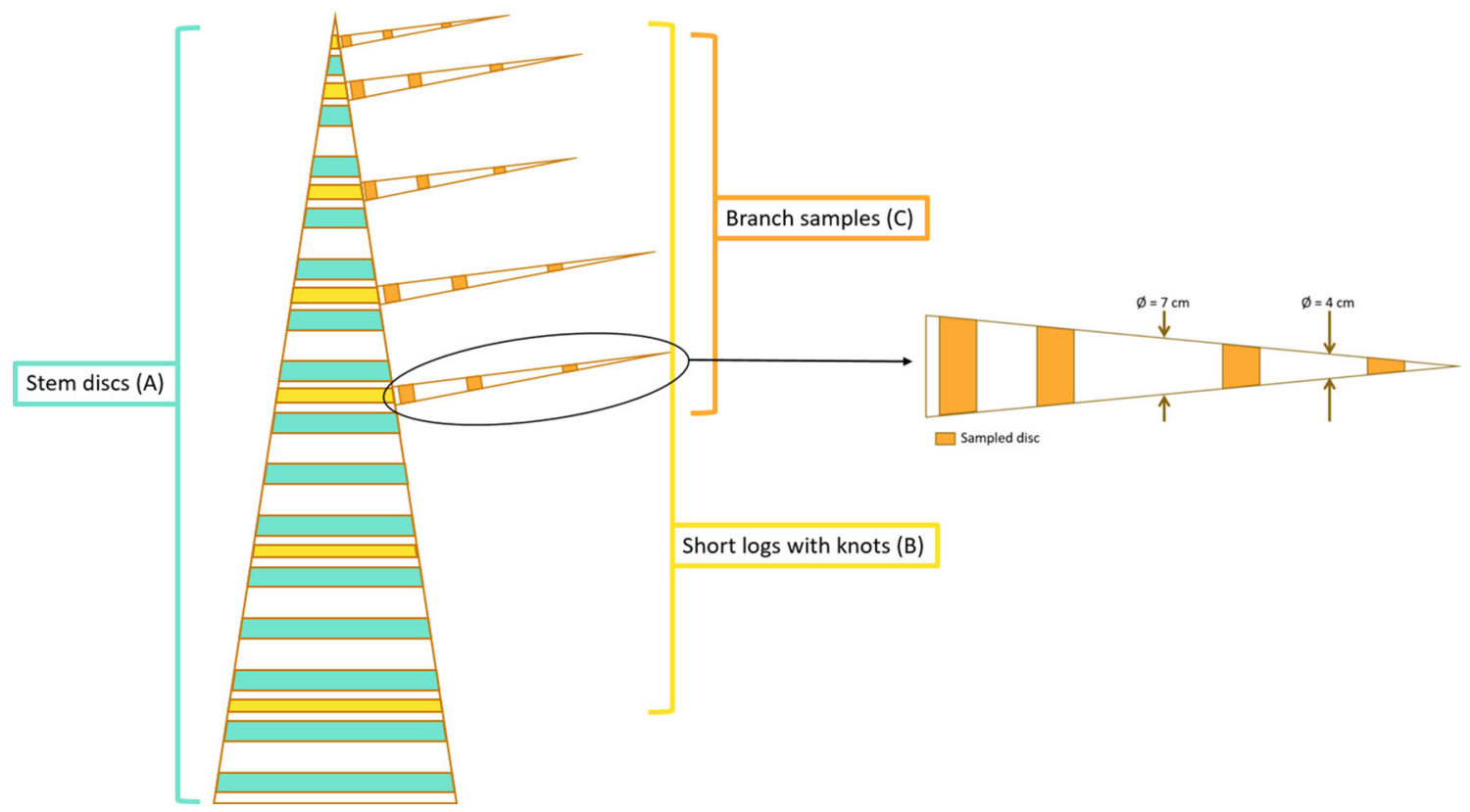

Fig. 1 Description of disc sampling within the tree (on the left). The stem discs ( 15 stem discs per tree) are in green. The short-logs containing knots (seven per tree: two below the crown base and five above) are in yellow. The branch discs (at least 10 branches per tree) are in orange. On the right: Sampling pattern along a branch belonging to the diameter class $>7 \mathrm{~cm}$. The leftmost disc is taken near the branch insertion. The other samples are taken in the middle of each predefined diameter class: $0-4 \mathrm{~cm}, 4-7 \mathrm{~cm}$ and $>7 \mathrm{~cm}$ 
virtually in order to compute density in clear of knots areas. The boundary between wood and bark was recorded manually for measuring the density of each component separately. Bark was segmented by thresholding to select pixels beyond the wood/bark boundary with density greater than $200 \mathrm{~kg} \cdot \mathrm{m}^{-3}$.

A slight shift in the wood/bark boundary positioning would not greatly affect the measurement of area and density of wood and bark, but for computing accurately $B D$ by this method, a good match between CT images in green and oven-dried states is required. This is specially problematic for bark whose surface area is much smaller than that of wood. For this reason, $B D$ of bark was rather estimated statistically from $D_{0}$ (see Section 2.4).

The short logs containing knots (B) and branch discs (C) were scanned only in oven-dried state because it would have been too difficult to get a good match between green and oven-dried images on such large samples (samples (B)) with irregular shape (samples (B) and (C)). $D_{0}$ was measured directly on the calibrated CT images, and $B D$ was estimated from $D_{0}$ (see Section 2.4).

The knots included in samples (B) were segmented manually using the "Gourmands" plug-in for ImageJ (Colin et al. 2010). The plug-in allows to put markers in the 3D space for delineating the stem pith and both sides of knots. The end of an outgoing knot (i.e., the knot/branch boundary) was fixed as much as possible at the "triple point" where stem wood meets knot wood and bark (left side of Fig. 2). The plug-in computes knot volume as a sum of truncated cones (right side of Fig. 2) and provides corresponding knot wood density. If there are two visible triple points, like in Fig. 2, the plug-in selects the triple point with the shortest distance to the pith (the rightmost point in this example).

The branch samples $(\mathrm{C})$ were placed in holding boxes to be scanned in batches of about 10 samples (Appendix A). An ImageJ macro was developed for processing semiautomatically the images. The mean $D_{0}$ of each sample (including bark) was recorded.

\subsection{Relationship between basic density and oven-dry density}

Conversion formulas are available for converting wood density measured at a given moisture content to $B D$ (Williamson and Wiemann 2010). The theoretical relationship linking $B D$ to $D_{0}$ and wood shrinkage, by assuming linear shrinkage from fibre saturation point to oven-dry state, is:

$B D=D_{0} \cdot(1-S)$

where $S$ is the total volumetric shrinkage (unitless).

In previous works performed in our laboratory, $B D$ and $D_{0}$ were obtained on stem discs for several species, including A. alba and Ps. menziesii (Longuetaud et al. 2016), and linear regressions of the following form were fitted for verifying the theoretical relationship:

$B D=\alpha+\beta \cdot D_{0}$

where $\alpha$ and $\beta$ are the intercept and the slope of the regression, respectively.

Considering Eqs. 1 and 2, $\beta$ should estimate $1-S$ and $\alpha$ should be null. Actually, in most cases, $\alpha$ was found to be statistically not null because the shrinkage $S$ was itself varying with $D_{0}$.

Regressions were fitted with the X-ray measurements of $B D$ and measured $D_{0}$ performed on the 15 stem discs for each eight trees per species. The obtained parameters are given in Table 3. The same relationship was applied to all components (i.e., knots, branches and bark) of a given tree species.

\subsection{Basic density of the components}

For each tree, the $B D$ of the stem wood component (knotfree) was computed as the mean $B D$ of the 15 stem discs
Fig. 2 Manual segmentation of a knot in oven-dried state with Image J and "Gourmands" plug-in (on the left). The plug-in allows putting markers in the $3 \mathrm{D}$ space for delineating the stem pith and both sides of knots. The end of an outgoing knot (i.e., the knot/branch boundary) was fixed as much as possible at the "triple point" where stem wood meets knot wood and bark. 3D representation of the knot (on the right)
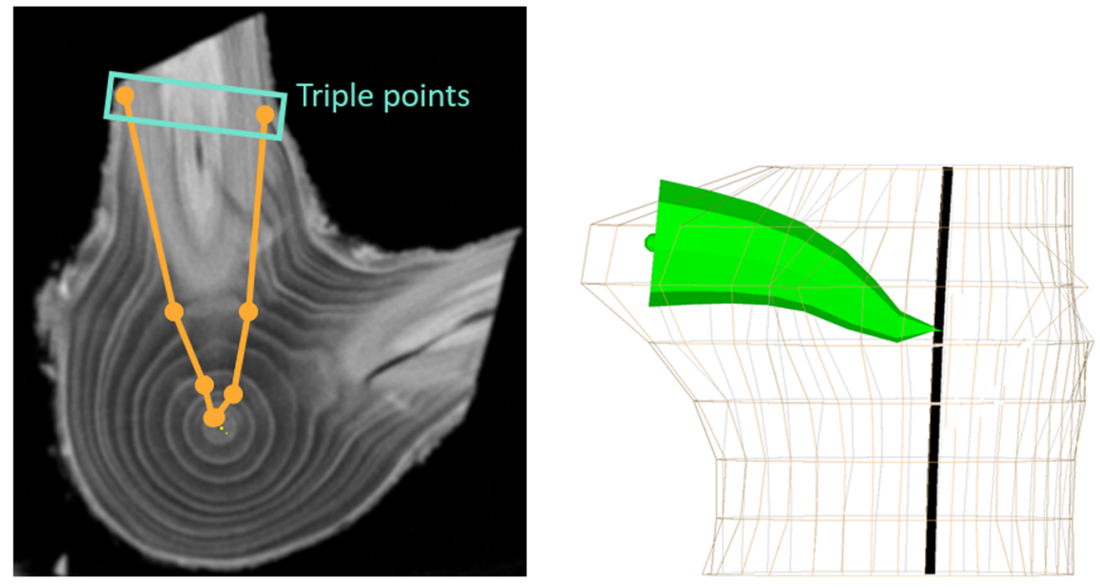
Table 3 Parameters of the statistical relationships used to convert $D_{0}$ into $B D$

\begin{tabular}{lll}
\hline Tree species & $\alpha\left(\mathrm{kg} / \mathrm{m}^{3}\right)$ & $\beta$ (unitless) \\
\hline Abies alba & 38 & 0.790 \\
& $* *$ & $* * *$ \\
Picea abies & 67 & 0.710 \\
& $* * *$ & $* * *$ \\
Pseudotsuga menziesii & - & 0.879 \\
& $\mathrm{NS}$ & $* * *$ \\
\hline
\end{tabular}

The stars indicate the significance: NS, $p \geq 0.05$ * $^{*}, p<0.05$; **, $p<0.01$; ***, $p<0.001$.

(wood part only) weighted by the volumes of wood of the stem short logs represented by each disc, i.e. a portion of the stem on either side of the disc calculated in such a way that each height fraction of the stem is associated with the disc closest to it.

In the same way, the $B D$ of the bark of each tree was converted from the mean $D_{0}$ of the bark of the 15 stem discs weighted by the volumes of bark contained in the stem short logs represented by each disc.

$B D$ of knots was estimated as the mean $B D$ of all the measured knots of each tree.

Due to technical constraints, the $B D$ of the knot component of Ps. menziesii was obtained only for five of the eight sampled trees.

The branch samples were separated into two groups: the branch insertion samples (closest to the stem) and the remaining samples of the branches.

For each tree, the $B D$ of the "branch insertion" component was computed as the mean $B D$ of the branch insertion samples. The average of the remaining branch samples (one to three samples per branch, depending on the branch size class) was computed to be the $B D$ of the "branch without insertion" component. The reason for this distinction is a significantly much higher wood density at the branch insertion (first $50 \mathrm{~cm}$ from the stem) than in the remaining part of the branch where the density is relatively constant as shown by Hakkila (1971) and in an unpublished work that we have done recently on our three species.

At this stage, a mean $B D$ value was available for each component of each tree. For each species, the mean $B D$ of each tree component was computed by averaging the corresponding values for the eight trees. Last, the $B D$ of each individual tree was computed by averaging the $B D$ of its components weighted by their volume as computed in Section 2.6. Then, the mean $B D$ of the eight trees per species was computed and given in Appendix B as the lines "Aboveground total".

\subsection{Volume of the components}

For each tree, over-bark stem volume $\left(V_{s t e m}^{o b}\right)$ was obtained by summing truncated cones defined by the distance between the stem discs (A) and their over-bark areas. Underbark stem volume $\left(V_{\text {stem }}^{u b}\right)$ was measured in the same way using the under-bark disc areas. The over-bark and under bark disc areas were measured on the CT images obtained from X-ray scans in green state.

The volume of stem bark was obtained by difference between over-bark and under-bark stem volumes.

The volume of knots was assessed by assuming a constant ratio $k=1 \%$ of knot volume to $V_{\text {stem }}^{o b}$ for Albies alba and $P$. abies and $k=1.3 \%$ for Ps. menziesii. These ratios were measured on a subsample of 11 trees of Albies alba and 9 trees of Ps. menziesii from Longuetaud et al. (2016) that were entirely X-ray scanned, and for which total knot volume was assessed manually on CT images. The knot ratio per tree varied from 0.5 to $1.4 \%$ for Albies alba and from 0.9 to 1.7 for Ps. menziesii.

For assessing the volume of branches, the total aboveground volume was first estimated by using an expansion factor (Pretzsch 2009). The volume expansion factors ( $V E F$ ) proposed by Longuetaud et al. (2013) allow computing total aboveground over-bark volume $\left(V_{t o t}^{o b}\right)$ from the over-bark volume of the stem part with a diameter higher than $7 \mathrm{~cm}\left(V_{\text {stem }>7}^{o b}\right)$ :

$V_{\text {tot }}^{o b}=V_{\text {stem }>7}^{o b} \cdot V E F$

$V_{\text {stem }>7}^{o b}$ was computed with the same method as $V_{\text {stem }}^{o b}$, based on truncated cones. $V E F$ was computed for each tree from diameter at breast height and total tree height by using the species-specific models of Longuetaud et al. (2013). The total volume of branches was obtained by difference between $V_{\text {tot }}^{o b}$ and $V_{\text {stem }}^{o b}$, and then divided into "branch insertion" and "branch without insertion" by assuming that insertions accounted for $i=5 \%$ of the total volume of branches. The value of 5\% was assessed by detailed $\mathrm{X}$-ray scans of six entire branches, two for each species (unpublished work).

We finally obtained the volume of five tree components: volume of stem under bark without knots $\left(V_{\text {stem }} w / o\right.$ knots $)$, volume of bark $\left(V_{\text {bark }}\right)$, volume of knots $\left(V_{\text {knots }}\right)$, over-bark volume of branch insertions $\left(V_{b r}\right.$ ins $)$ and over-bark volume of the remaining part of the branches $\left(V_{b r}\right.$ w/o ins $)$ :

$$
\begin{aligned}
V_{\text {stem } w / o \text { knots }} & =V_{\text {stem }}^{u b}-V_{\text {knots }} \\
V_{\text {bark }} & =V_{\text {stem }}^{\text {be }}-V_{\text {stem }}^{u b} \\
V_{\text {knots }} & =k \cdot V_{\text {stem }}^{\text {ob }} \\
V_{\text {br ins }} & =i \cdot\left(V_{\text {tot }}^{\text {ob }}-V_{\text {stem }}^{o b}\right) \\
V_{\text {br w/o ins }} & =(1-i) \cdot\left(V_{\text {tot }}^{\text {ob }}-V_{\text {stem }}^{o b}\right)
\end{aligned}
$$


where $V_{\text {stem }}^{u b}$ is the under-bark volume of stem, $V_{\text {stem }}^{o b}$ the over-bark volume of stem and $V_{t o t}^{o b}$ the total aboveground over-bark volume.

\subsection{Biomass of the components}

For each tree, the biomass of each component was computed as the product of the component $B D$ and volume. A first estimate, Biomass $s_{1, \text { tree,component }}$ was obtained by using the actual value of the $B D$ for the component and a second one by using the $B D$ of the knot-free stem wood measured at breast height as it is often done (Biomass $s_{2, \text { tree,component). }}$. The relative difference between the two methods was computed as:

$$
\begin{aligned}
& \Delta B_{\text {tree,component }}^{\text {rel }} \\
& =\frac{\text { Biomass }_{2, \text { tree,component }}-\text { Biomass }_{1, \text { tree,component }}}{\text { Biomass }_{1, \text { tree,component }}} \times 100
\end{aligned}
$$

For each species and component, a mean relative difference was computed based on the eight trees. A confidence interval of each mean relative difference was computed providing information on the significance. Note that the relative difference can be interpreted in the same way in terms of $B D$ by simplifying by the volume of the component.

The same approach was applied for the whole tree. The sum of the five components (knot-free stem wood, stem bark, knots, branch insertions and branches without insertions) gave an estimate of the total aboveground biomass of each tree:

$$
=\sum_{\text {component }=1}^{\text {Biomass } 1, \text { tree }} \text { BD tree,component } \times V_{\text {tree,component }}
$$

This value was compared to the biomass that would be obtained by assuming a constant $B D$ equal to the value measured at breast height and applied for the whole tree:

Biomass $_{2, \text { tree }}=B D_{1.30 m, \text { tree }} \times V_{\text {tot }, \text { tree }}^{\text {ob }}$

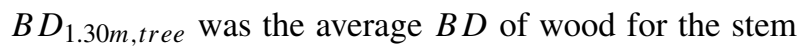
disc taken at breast height for the considered tree. In the same way as for each component, a relative biomass difference was computed for each tree as:

$\Delta B_{\text {tree }}^{\text {rel }}=\frac{\text { Biomass }_{2, \text { tree }}-\text { Biomass }_{1, \text { tree }}}{\text { Biomass }_{1, \text { tree }}} \times 100$

The mean value $\Delta B^{r e l}$ and its confidence interval were computed for each species from these eight $\Delta B_{\text {tree }}^{\text {rel }}$ values.

The $\mathrm{R}$ software was used for the analysis (R Core Team 2018).

\section{Results}

\subsection{Mean basic density of the tree components}

On average for all three species, the density values are in the following decreasing order: knots, branch insertions, branches without insertion, bark and knot-free stem wood (Fig. 3 and Appendix B to compare with the values reported in public databases in Appendix D). Except for Ps. menziesii, the mean $B D$ of knots, branch insertions, branches without insertion and bark were all larger than the breast height $B D$ that was of 407,356 and $453 \mathrm{~kg} \cdot \mathrm{m}^{-3}$ for A. alba, P. abies and Ps. menziesii, respectively.

\subsection{Effect of tree species, stand density and tree component on basic density}

For each tree component, the $B D$ averaged by tree is represented as a function of $D B H$ (Fig. 4). For each species and each component, a Pearson's correlation coefficient $r$
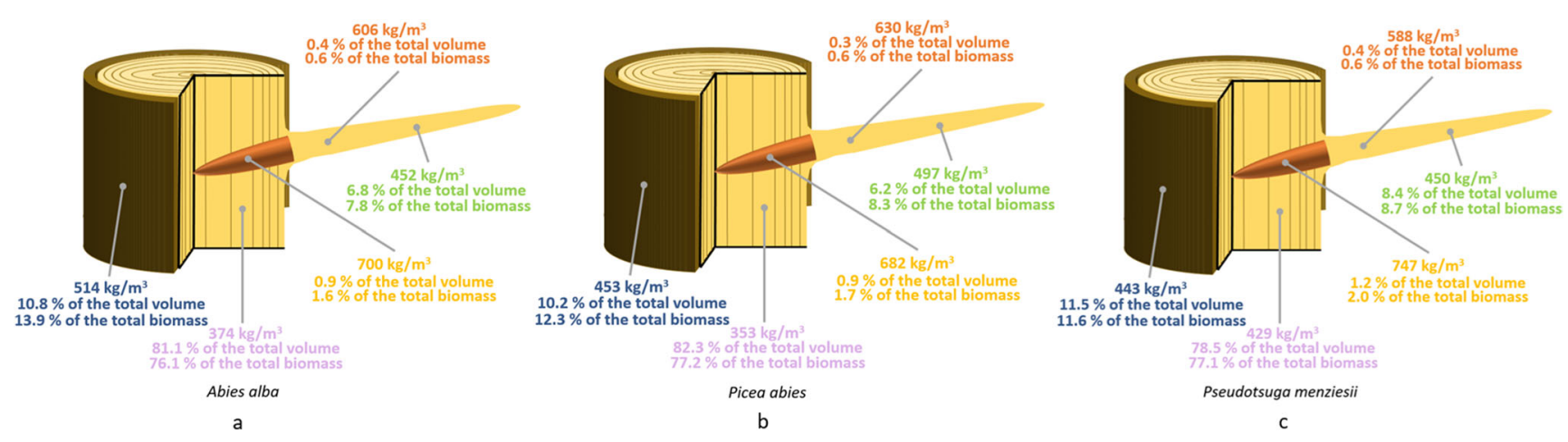

Fig. 3 Mean measured basic density, volume fraction and biomass fraction of each tree component for A. alba (a), P. abies (b) and Ps. menziesii (c) 

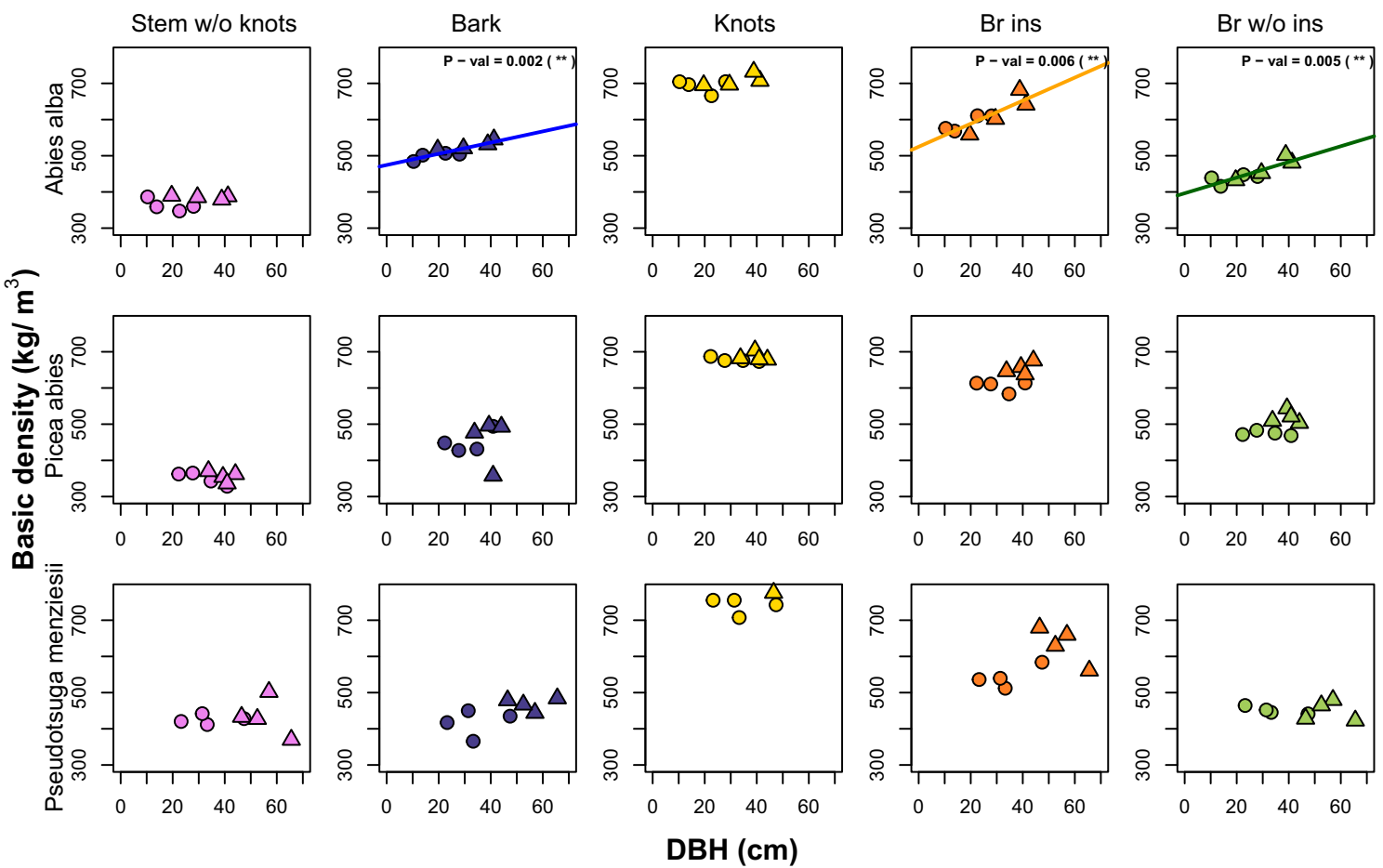

Fig. 4 Relationship between the mean $B D$ of tree components and the $D B H$ of the tree for every tree species in unthinned (circles) and heavily thinned (triangles) plots. Stem $w / o$ knots is the stem under bark without knots, $\mathrm{Br}$ ins are the branch insertions and $\mathrm{Br}$ w/o ins

was calculated and its significance was assessed (Pearson test with function cor.test of R statistical software).

The $r$ coefficients obtained were not significant (Table 4), except for $A$. alba for which $B D$ of bark and branches increased with $D B H . B D$ of bark and branch insertions for Ps. menziesii ( $r=0.64$ and 0.55 , respectively) and to a lesser extent $B D$ of branch insertions for P. abies $(r=0.53)$ seemed to increase with $D B H$ as well (Fig. 4) but it was not statistically significant probably due to the small sample size.

Student $t$ tests performed for comparing $B D$ of trees from unthinned and heavily thinned plots (Table 5) did not show significant differences, except for the bark of A. alba are the branches without their insertion. The regression line and the $p$ value of the slope are indicated in the plot when it was significant. The stars indicate the $p$ value significance: NS, $p \geq 0.05$;,$p<0.05$; **, $p<0.01 ; * * *, p<0.001$

and the branches of $P$. abies that were both denser in the heavily thinned plots.

Figure 5 and Table 6 show $B D$ variations for each tree component as a function of the sample diameters (i.e., stem, knot or branch diameters). The $B D$ of all components of $A$. alba tended to increase with their size. The correlation was particularly strong for bark, branch insertions and branches without insertion $(r=0.68,0.72,0.73$, respectively). The same increase in $B D$ with the sample diameter was observed for branches (insertions and without insertion) and to a lesser extent for knots of $P$. abies. A significant negative correlation $(r=-0.49)$ was observed for the stem wood of $P$. abies. For Ps. menziesii, a low but significant positive
Table 4 Pearson's correlation coefficient $r$ between $B D$ and $D B H$ for each tree component and each species where stem $w / o$ knots means stem under bark without knots, $B r$ ins means branch insertions and $\mathrm{Br}$ w/o ins means branches without insertions

\begin{tabular}{llllll}
\hline Tree species & Stem w/o knots & Bark & Knots & Br ins & Br w/o ins \\
\hline Abies alba & 0.21 & 0.90 & 0.45 & 0.86 & 0.87 \\
& NS & $* *$ & NS & $* *$ & $* *$ \\
Picea abies & -0.48 & 0.18 & -0.05 & 0.53 & 0.47 \\
& NS & NS & NS & NS & NS \\
Pseudotsuga menziesii & -0.04 & 0.64 & 0.20 & 0.55 & -0.22 \\
& NS & NS & NS & NS & NS \\
\hline
\end{tabular}

The stars indicate the $r$ significance: NS, $p \geq 0.05$ * $^{*}, p<0.05$ * $^{* *}, p<0.01$; ***, $p<0.001$ 
Table $5 t$ tests of $B D$ between the two thinning modalities: average values for heavy thinning on the left and for no thinning on the right where stem w/o knots means stem under bark without knots, $\mathrm{Br}$ ins means branch insertions and $\mathrm{Br}$ w/o ins means branches without insertions

\begin{tabular}{lllllll}
\hline Tree species & Stem at breast height & Stem w/o knots & Bark & Knots & Br ins & \multicolumn{1}{c}{ Brw/o ins } \\
\hline Abies alba & $410.99 ; 402.23$ & $385.43 ; 363.19$ & $528.52 ; 499.21$ & $707.6 ; 692.87$ & $620.87 ; 591.21$ & $466.88 ; 436.16$ \\
& NS & NS & $*$ & NS & NS & NS \\
Picea abies & $355.04 ; 356.77$ & $355.75 ; 349.59$ & $455.77 ; 450.22$ & $685.97 ; 677.97$ & $654.49 ; 605.4$ & $519.45 ; 474.5$ \\
& NS & NS & NS & NS & $* *$ & $*$ \\
Pseudotsuga menziesii & $467.54 ; 438.75$ & $432.9 ; 425.47$ & $468.36 ; 416.87$ & $775.66 ; 740.13$ & $632.34 ; 542.9$ & $448.73 ; 450.74$ \\
& NS & NS & NS & - & $*$ & NS \\
\hline
\end{tabular}

The stars indicate the $t$ test significance: NS, $p \geq 0.05$ * $^{*}, p<0.05 ; * *, p<0.01$; ***, $p<0.001$
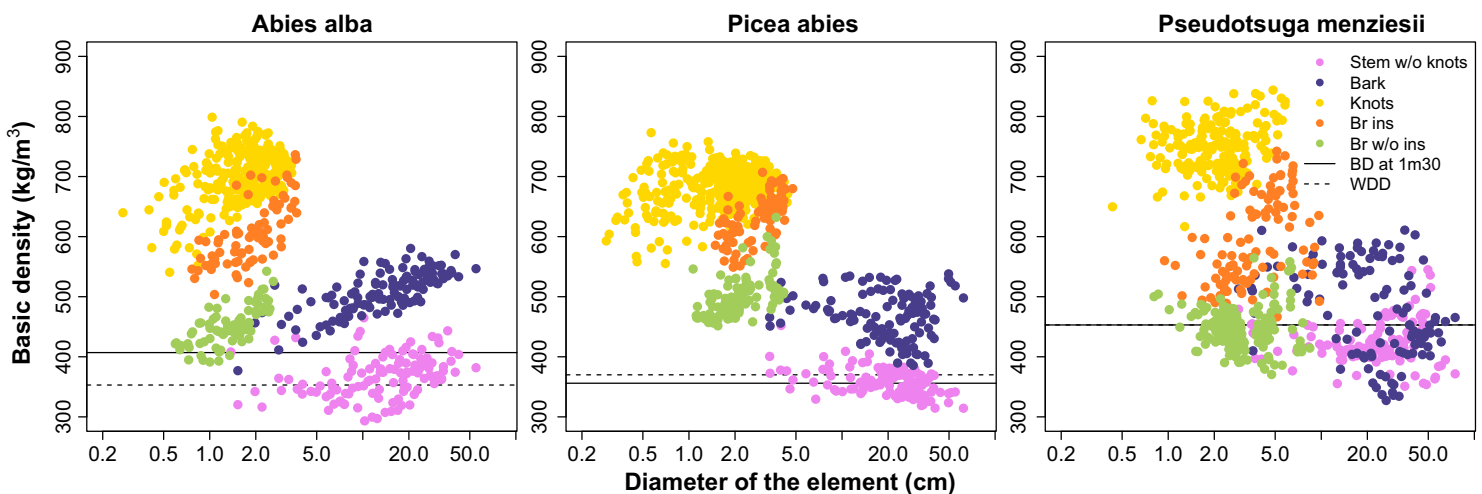

Fig. $5 B D$ of tree components as a function of their corresponding diameter (i.e., diameter of each sample) for each tree species (for bark component the stem diameter was used): knot-free stem wood (stem w/o knots; purple), bark (blue), knots (yellow), branch insertions ( $\mathrm{Br}$ ins; orange), branches without insertion ( $\mathrm{Br} w / \mathrm{o}$ ins; green). The horizontal line is the mean $B D$ measured at breast height while the dotted line represents the Global Wood Density Database value

Table 6 Pearson's correlation coefficient $r$ between component $B D$ and diameter of all tree components for each tree species (stem diameter for bark) where stem $w / o$ knots means stem under bark without knots, $\mathrm{Br}$ ins means branch insertions and $\mathrm{Br} w / o$ ins means branches without insertions

\begin{tabular}{|c|c|c|c|c|c|}
\hline Tree species & Stem w/o knots & Bark & Knots & $\mathrm{Br}$ ins & $\mathrm{Br}$ w/o in \\
\hline \multirow[t]{2}{*}{ Abies alba } & 0.35 & 0.68 & 0.41 & 0.72 & 0.73 \\
\hline & $* * *$ & $* * *$ & $* * *$ & $* * *$ & $* * *$ \\
\hline \multirow[t]{2}{*}{ Picea abies } & -0.49 & -0.03 & 0.21 & 0.67 & 0.59 \\
\hline & $* * *$ & NS & $* * *$ & $* * *$ & $* * *$ \\
\hline \multirow[t]{2}{*}{ Pseudotsuga menziesii } & 0.07 & -0.33 & 0.26 & 0.32 & 0.03 \\
\hline & NS & $* * *$ & $* * *$ & $* * *$ & NS \\
\hline
\end{tabular}

The stars indicate the $r$ significance: NS, $p \geq 0.05$ * $^{*} p<0.05 ; * *, p<0.01 ; * * *, p<0.001$ 


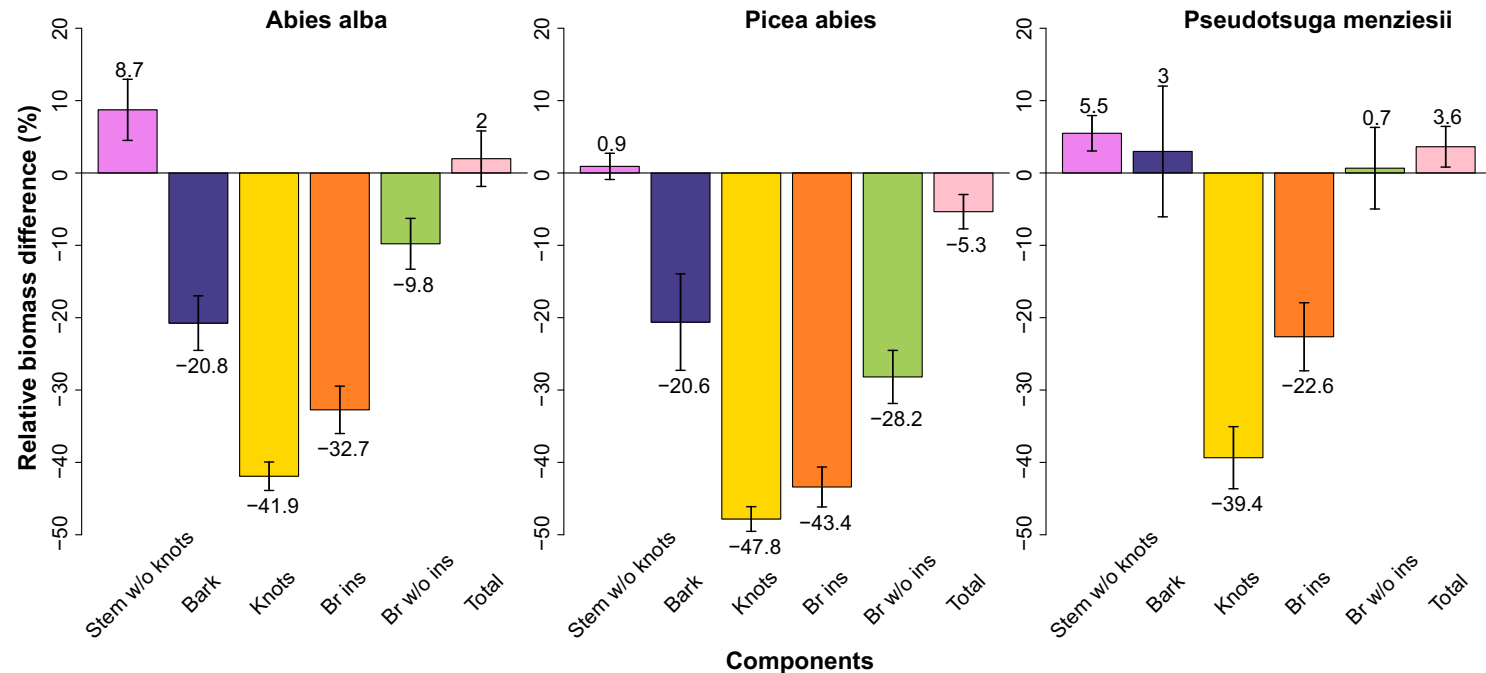

Fig. 6 Mean relative biomass differences $\Delta B^{r e l}$ between biomasses calculated with the breast height basic density value and with the actual basic density of the component relatively to the actual basic density of

correlation was observed for branch insertions $(r=0.32)$ and low negative correlations for bark $(r=-0.33)$ and knots $(r=-0.24)$. This decrease of bark density with stem diameter seemed to reflect actually a stronger effect of height ( $r=0.74$ between $B D$ of bark and height from the ground).

The variations of the component $B D$ with height in the tree (Appendices 4 and 5) are consistent with the previous observations, considering that the size of each element decreases with the height in the tree.

\subsection{Biomass estimates}

Figure 6 shows the relative error on biomass estimates when using the $B D$ measured at breast height instead of average component-specific $B D$. A value of $0 \%$ means that taking into account component-specific $B D$ does not change the quantity of biomass compared to an estimation made on the basis of the density at breast height.

The biomass of bark (except for Ps. menziesii), knots and branches (except branch part without insertion for $P S$. menziesii) was strongly underestimated when using $B D$ measured at breast height: by about 40 to $50 \%$ for the knots whatever the species and $20 \%$ for the bark of $A$. alba and $P$. abies.

For the knot-free stem wood, on the contrary, the biomass was overestimated by $8.7 \%$ for $A$. alba and by $5.5 \%$ for $P$ s. menziesii.

The use of the average $B D$ at breast height results in an overestimation by $3.6 \%$ for Ps. menziesii and an underestimation by $5.3 \%$ for P. abies of the total aboveground biomass (Fig. 6), whereas the difference was not significant for $A$. alba. the component. Stem $w / o$ knots is the stem under bark without knots, $\mathrm{Br}$ ins are the branch insertions and $\mathrm{Br} w / o$ ins are the branches without their insertion

In complement, a non-parametric test giving the significance of the difference between the two biomass estimates for each component and each species was made (WilcoxonMann-Whitney test). The test confirmed the results and significance of the differences of Fig. 6 except for knots of Ps. menziesii. This can be explain by the fact that only five Ps. menziesii trees were sampled for knots while eight trees were sampled for the other species.

\section{Discussion}

\subsection{Difference of $B D$ between tree components}

Our values of $B D$ at breast height were slightly higher than values found in available databases for A. alba, lower for $P$. abies and similar for Ps. menziesii.

The mean knot-free stem $B D$ was lower than the $B D$ at breast height for all the species and the difference was significant for A. alba and Ps. menziesii. This is a commonly found result as in Cown (1967) for Ps. menziesii or Wassenberg et al. (2015) for various species. And it perfectly confirms the results obtained by Longuetaud et al. (2017) on other trees from the same species.

Bark, knot and branch components were all found denser than the knot-free stem wood, although it was less pronounced for Douglas fir. This confirms what we have seen in the literature.

Miles and Smith (2009) also found bark density higher than stem wood density for several North American Abies species $^{1}\left(360 \mathrm{~kg} \cdot \mathrm{m}^{-3}\right.$ for stem wood and $490 \mathrm{~kg} \cdot \mathrm{m}^{-3}$ for

\footnotetext{
${ }^{1}$ Not including A. alba.
} 
bark in average) and $P$. abies $\left(360 \mathrm{~kg} \cdot \mathrm{m}^{-3}\right.$ for stem wood and $440 \mathrm{~kg} \cdot \mathrm{m}^{-3}$ for bark). For Ps. menziesii, they found the opposite with stem slightly denser than bark $\left(450 \mathrm{~kg} \cdot \mathrm{m}^{-3}\right.$ vs. $440 \mathrm{~kg} \cdot \mathrm{m}^{-3}$ ). Overall, our results are very close and in total agreement with Miles and Smith (2009) for the comparison between bark density and $B D$ at breast height (more widely used than knot-free stem density). Our values for $B D$ at breast height and bark density were respectively 407 and $514 \mathrm{~kg} \cdot \mathrm{m}^{-3}$ for A. alba, 356 and $453 \mathrm{~kg} \cdot \mathrm{m}^{-3}$ for P. abies and 453 and $443 \mathrm{~kg} \cdot \mathrm{m}^{-3}$ for Ps. menziesii. Dibdiakova and Vadla (2012), who studied the density of P. abies bark, also found it denser than density of the stem wood regardless of the height in the tree. The same result was reported by Petráš et al. (2019) for P. abies and other species.

Anatomical features could explain the high density of bark. For Douglas fir for instance, Patel (1975) observed that phloem contained fibres with very thick walls and narrow lumen. The high density of bark could also be related to a higher concentration of inorganic elements. Indeed, Rothpfeffer and Karltun (2007) found on P. abies that the concentration of inorganic elements is more than 2 to 15 times higher in bark than in the stem wood. For Pinus sylvestris, when wood is burned, the quantity of ashes is five times more important for bark than for stem wood (Filbakk et al. 2011). Moreover, bark has a high concentration of tannins (Norin and Winell 1972) that could increase the density by filling the pores.

For the density of knots, few studies are available due to the difficulty of carrying out the measurements. For P. abies, Hakkila (1971) found the highest density in the knots. Lehtonen (1978) obtained similar results with knots $351 \mathrm{~kg} \cdot \mathrm{m}^{-3}$ denser than stem wood for Pinus sylvestris and $490 \mathrm{~kg} \cdot \mathrm{m}^{-3}$ denser for $P$. abies. The mean $B D$ of knots calculated from Gartner (1995) for P. abies is of $673 \mathrm{~kg} \cdot \mathrm{m}^{-3}$, very close to $682 \mathrm{~kg} \cdot \mathrm{m}^{-3}$ in our study. In our study, the differences between knot density and $B D$ measured at breast height were approximately $293 \mathrm{~kg} \cdot \mathrm{m}^{-3}$ for A. alba, $326 \mathrm{~kg} \cdot \mathrm{m}^{-3}$ for P. abies and $294 \mathrm{~kg} \cdot \mathrm{m}^{-3}$ for Ps. menziesii. Several hypotheses can be made concerning the higher density of knots: their high content in extractives (Kebbi-Benkeder et al. 2015; Kebbi-Benkeder et al. 2016), the presence of compression wood (Wegelius 1940) and the narrow ring widths within the knots. Indeed, it is known that for most softwood species the stem wood density increases when the ring width decreases due to a higher latewood proportion (e.g., Koga and Zhang (2004) for Abies balsamea, Franceschini et al. (2013) for P. abies, Cown (1967) for Ps. menziesii).

Branches were generally denser than stem wood for softwoods (e.g., McKimmy and Ching 1968, Hakkila 1971, Lehtonen 1978, Gryc et al. 2011, Dibdiakova and Vadla 2012). This is in accordance with our results. Hakkila
(1971) found branches denser than stem wood for Pinus sylvestris and P. abies, and McKimmy and Ching (1968) obtained similar result for $P$ s. menziesii. This is also the case of Dibdiakova and Vadla (2012) and Gryc et al. (2011) on P. abies. Lehtonen (1978) found that the difference between branch density and stem wood density was of $221 \mathrm{~kg} \cdot \mathrm{m}^{-3}$ for Pinus sylvestris and $407 \mathrm{~kg} \cdot \mathrm{m}^{-3}$ for P. abies. Branches contain more extractives like resin than stem wood, especially near the insertion (Wegelius 1940; Hakkila 1971). However, McKimmy and Ching (1968) found no significant difference in specific gravity due to extractives. The high content of compression wood at the proximal part of softwood branches (Wegelius 1940; Hakkila 1971; Spicer and Gartner 1998) could also contribute to increase their high density. Moreover, the high density of branches could be related to their slow radial growth associated to narrow annual rings (Franceschini et al. 2013) as for the knots of which they are the extension. Finally, there are more inorganic elements in branches than in stem wood and bark (Rothpfeffer and Karltun 2007).

\subsection{Effects of growth rate and tree size on basic density}

Small differences in $B D$ of the tree components were found between unthinned and heavily thinned plots. Hypothesis $\mathrm{H} 1$ is therefore somewhat supported but these results should be considered with caution since there were only four trees in each modality. Moreover, the difference was in favour of the heavily thinned stands regardless of tree component that is the opposite of what was expected.

The effect of tree $D B H$ on $B D$ was also rather small, except for bark and branches of $A$. alba whose $B D$ tended to increase with $D B H$. This is in line with the previous observation since $D B H$ was on average higher in heavily thinned stands.

All the trees from the same species having the same age (or the same age range for $A$. alba), the biggest trees had in average wider growth rings at breast height than the smaller ones. One could have therefore expected that the $B D$ (of knot-free stem wood at least) would be higher for the slowest growing trees, due to the already mentioned relationship usually observed between wood density and ring width. Actually, looking at the average ring width and $B D$ at breast height, the relationship was only observed for P. abies (Appendix 6). It is important to note that the density-ring width relationship is generally obtained for the individual rings of a given tree measured at breast height and not for average values of density and ring width that are compared between trees. When they were young, out of competition, the trees from both modalities probably grew at the same speed. And when competition appeared, the trees of the heavily thinned modality started to grow faster. As 
a result, the proportion of juvenile wood is probably lower in these trees. And in general, the stem wood density is lower in juvenile wood than in mature wood for softwoods (Lachenbruch et al. 2011). This could maybe explain the lower $B D$ in unthinned stands due to a higher proportion of juvenile wood of lower density.

The higher density observed for bark and branches of some species for the bigger trees or for trees from the heavily thinned stands could be due to a higher content of inorganic elements in these components since these trees had an easier access to resources.

\subsection{Effects of component diameter and height in the tree on basic density}

The observed variations of the knot-free $B D$ with the stem diameter are coherent with the vertical variations reported by Longuetaud et al. (2017): a decrease with the height in the tree for A. alba and Ps. menziesii, contrary to P. abies for which $B D$ increased with height.

As above, bark density of Ps. menziesii was found to decrease with stem diameter. This result could be related to the changes in bark structure from the stem base (flaky patches of cork) to the top levels (rather smooth and only slightly fissured) that were reported for this species (Cardoso et al. 2019). It was the opposite for A. alba with a strong increase of bark $B D$ with the stem diameter that could be due to differences in strategy between species. Depending on the environment (cold, fire, biotic attacks), would it be better to invest in a thicker and less dense bark or on the contrary in a thinner and denser one?

Lehtonen (1978) pointed out for P. abies that the bigger the knot was, the less dense it was. Our results do not confirm this observation: The bigger knots (all trees together) were denser for all species. For A. alba, the clear decreasing trend of $B D$ with height in the tree could be explained by variations in the extractive content of knots. Indeed, Kebbi-Benkeder et al. (2017) observed that concentrations in hexane and acetone extracts decreased from the crown base toward the tree tip. They attributed the smaller extractive concentrations in the highest knots to their young age and their higher content of sapwood.

For branches of the three species, $B D$ increased with the branch diameter and generally decreased with insertion height. These results are in agreement with those of Hakkila (1971) for spruce: branches near the bole were denser than branches far from the bole, and when branches were classified in diameter classes, the density was higher for the thickest branches. Lehtonen (1978) showed that wood density of branch stumps decreases with increasing branch diameter for $P$. abies. The author mentions that his result is in agreement with Boutelje (1966) but in contrast with Enčev (1962) (in Lehtonen (1978)) for the same species. These contradictory results could be attributed to geographical variations or genetical factors.

\subsection{Total aboveground biomass estimates}

The biomass of bark, knots and branches was in most cases largely underestimated when using $B D$ measured at breast height. This result is very interesting for these tree components that are particularly rich in extractives and that are specifically targeted for the development of a green chemistry industry. This means for example that the amount of extractives in the knots was also underestimated by 40 to $50 \%$. On the other hand, the knots represented only 1.6 to $2 \%$ of the total biomass, which is very low and relatively negligible. Bark had a higher weight with 11.6 to $13.9 \%$ of the total biomass depending on the species. On the contrary, the biomass of the knot-free stem wood was significantly overestimated with $B D$ measured at breast height for $A$. alba and Ps. menziesii since $B D$ is higher at the lower part of the stem for these species. Comparable results were observed by Longuetaud et al. (2017) for A. alba (overestimation by 5\%), by Cown (1967) and Longuetaud et al. (2017) for Ps. menziesii (overestimation by 5\%) and by Repola (2006) for $P$. abies (overestimation by less than $1 \%$ ). Finally, since the stem volume is bigger than the volume of all other tree components, the total aboveground biomass was significantly underestimated by $5.3 \%$ for $P$. abies and overestimated by $3.6 \%$ for $P$ s. menziesii when $B D$ at breast height was used. There is a compensatory effect between the reference breast height density, which is generally too high in relation to $B D$ of the whole stem, and $B D$ of the other components (bark, knots and branches) which is largely underestimated but whose volumes are smaller. The impact of accounting $B D$ of each component (Hypothesis $\mathrm{H} 2$ ) is clear for each component but thanks to this compensatory effect, the biases on the total aboveground biomass remain relatively small, even if it is statistically significant. For Sagang et al. (2018), using $B D$ at the base of the tree rather than the weighted average density (stem wood, branches, leaves and reproductive parts) leads to overestimating the total aboveground biomass of tree by $10 \%$ based on fifteen tropical species. In practice, applying this volume $\times$ density approach for evaluating biomass of each component as well as total aboveground biomass would require models accounting for the $B D$ variations of each component (at intra- and inter-tree levels) and models for better assessing the volume of each component (CorralRivas et al. 2017). We are now working on such models. Furthermore, the method has to be compared with direct approaches predicting biomass of some tree components through allometric equations (Gómez-García et al. 2015) and validated with biomass field measurements. But the advantages of volume $\times$ density approaches are numerous: 
volume data are widely available through forest inventories, both volume and biomass of tree components are provided, and with the development of the LiDAR technology for measuring the volume of tree components (e.g., Stovall et al. 2017 ), it is necessary to have the corresponding $B D$ values.

\subsection{Methodological aspects}

In this exploratory study, trees were measured very intensively. This was never done before. The field operations followed by drying and density measurements were both complex and time consuming, justifying that only eight trees per species could be processed. For a Student $t$ test with four trees in each group, a significance level of 0.05 , $B D$ standard deviation of about $25 \mathrm{~kg} \cdot \mathrm{m}^{-3}$ for each group and mean difference between the two groups of about $50 \mathrm{~kg} \cdot \mathrm{m}^{-3}$, the power of the test was about 0.7 (function pwrt.test of $\mathrm{R}$ ), which is acceptable. Nevertheless, our results have to be verified and validated on more trees. This study should help reducing the sampling intensity within trees so that more trees can be sampled for the same costs.

The relations used to convert the oven-dry density into $B D$ can be criticised. They were calibrated on stem wood values and used for the other components. In an unpublished work on $P$. abies, we adjusted the statistical equation both for stem wood and branch samples (for which $B D$ was measured by water displacement method), all issued from one single tree. An important result of this work was that the relationships between oven-dry density and $B D$ were similar for stem wood and branch components. By using the statistical relationships, we assumed that they were applicable to all components of each species. From our point of view, this approach is better than applying the mechanistic equations involving shrinkage because it is clear that the shrinkage value varies depending on component and component density. Further research will be necessary to better assess $B D$ of components like bark whose properties are probably far from those of stem wood.

The volume of the branch insertion component used is an approximation. Some observations on six entire X-rayed branches (not published) confirmed that the wood density is much higher in the first $50 \mathrm{~cm}$ of branches in agreement with Hakkila (1971). This helped us estimate the volume of this tree component and then the weight of 5\% to apply in our biomass computations by also taking into account the fact that the discs sampled at the branch insertions represent rather the first $10 \mathrm{~cm}$ of branches. This point should be studied in more detail in a further study.

We measured the actual volume of the bark component thanks to the CT scanner by analysing images. But volume of bark is often determined from tape measures first over and then under bark, or in the field with a Swedish bark gauge. The problem is that for the part of tree stems (most of the time only the bottom part) with a rough and cracked bark (depending on the species and tree age), the tape measure overestimates the actual bark volume. For our biomass estimates, we used the actual bark volumes of our trees: on average $11.5,10.9$ and $12.6 \%$ of the total over-bark stem volume, for A. alba, P. abies and Ps. menziesii, respectively, against $11 \%$ for $A$. alba and P. abies, and $14.5 \%$ for $P$ s. menziesii as obtained in the EMERGE project (Bouvet and Deleuze 2013) and then published in the online FCBA Memento 2019. Logically, the difference is more important for Ps. menziesii than for species with a smooth bark.

The knot manual segmentation method has already been discussed in Billard et al. (2019)

\section{Conclusion}

Very large differences in $B D$ were observed between the studied tree components (stem wood, bark, knots and branches). These differences should be taken into account to estimate correctly the biomass of each tree component but also the total aboveground biomass of tree in avoiding biases. In particular, the biomass of knots and bark was strongly underestimated when using a $B D$ measured at breast height or provided by available databases. These two tree components are targeted to be used as sources of extractives in the development of an industry based on wood chemistry and the assessment of their availability in terms of biomass at the resource scale must be accurate.

A lighter sampling protocol has to be proposed in order to increase the number of trees and environmental contexts.

The next step will be to study the variation of basic density within each component and to develop predictive models or (1) the vertical variation of density along the stem and the bark, and (2) the variation along the branch, including the knot. Correction factors starting from the $B D$ measured or estimated at breast height should be developed with the objective to provide accurate biomass estimates for each component of each species at the resource level. In further work, the results of such volume $\times$ density method have to be compared with allometric approaches for assessing aboveground biomass and with biomass field measurements.

Acknowledgments We would like to thank Christine Deleuze (ONF) for her help in achieving this study, Vincent Rousselet, Frédéric Bordat, Loc Dailly and Adrien Contini for the sampling in the forest and measurements at the laboratory, and Charline Mola for the CT scanner acquisitions. We are grateful to Adeline Motz and Daniel Rittié for the ring width measures. Also, we thank Chloé Agro, Lucie Heim and Leopold Bergé who worked during their Master theses on basic density and volume of knots, and Anaélle Rajaonarivo, Léa Bissieux and Bernard Poirot for the manual segmentation of knots. 
Funding SILVA laboratory is supported by a grant overseen by the French National Research Agency (ANR) as part of the Investissements d'Avenir program (ANR-11-LABX-0002-01, Lab of Excellence ARBRE). Antoine Billard's PhD is funded by ADEME and Région Grand-Est. This work was also funded by the ExtraFor_Est project coordinated by Francis Colin.

\section{Appendix 1: CT image of branch samples}

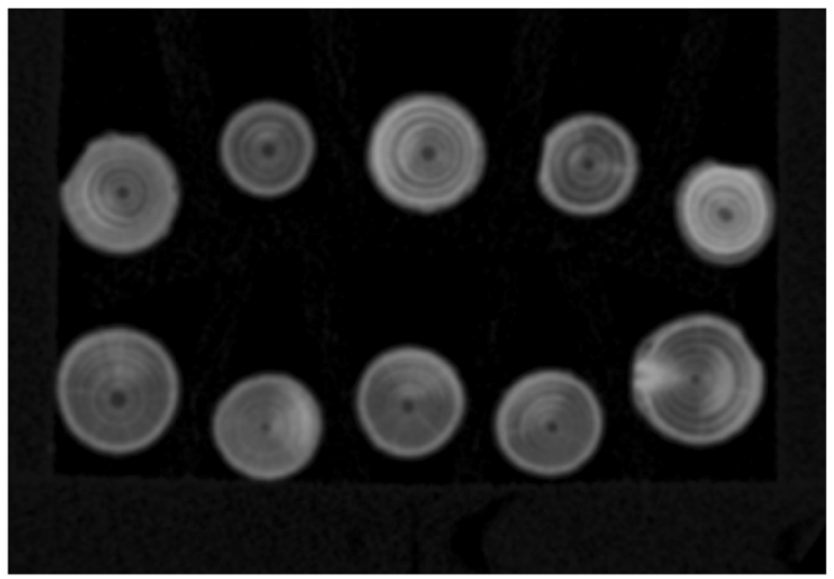

Fig. 7 CT image of 10 branch samples (C) in oven-dried state. The holding box made of a very light material is not visible by $\mathrm{X}$-rays

\section{Appendix 2: Basic density, volume and biomass for each component and species}

The table below shows, for each species and each compartment, the number of samples used to calculate the mean basic density of the component and the standard deviation of the basic density. The last two columns give the percentage of volume and biomass of the component in relation to the total volume/biomass of the tree. The average density of the tree is calculated from the averages of each component, weighted by their relative percentage of volume.

\section{Appendix 3: Basic density values reported in three public databases for three softwood species}

\begin{tabular}{llll}
\hline Tree species & $\begin{array}{l}\text { CARBOFOR } \\
\left(\mathrm{kg} / \mathrm{m}^{3}\right)\end{array}$ & $\begin{array}{l}\text { GWDD } \\
\left(\mathrm{kg} / \mathrm{m}^{3}\right)\end{array}$ & $\begin{array}{l}\text { TROPIX } \\
\left(\mathrm{kg} / \mathrm{m}^{3}\right)\end{array}$ \\
\hline Abies alba & 380 & 353 & 404 \\
Picea abies & 370 & 370 & 372 \\
Pseudotsuga menziesii & 430 & 453 & 448 \\
\hline
\end{tabular}

Basic density values for three softwood species as reported by three public databases: CARBOFOR (Loustau 2004) was a project about carbon sequestration in France

\begin{tabular}{|c|c|c|c|c|c|c|}
\hline Tree species & Component & No. of samples & $\begin{array}{l}\text { Mean BD } \\
\left(\mathrm{kg} \cdot \mathrm{m}^{-3}\right)\end{array}$ & Standard deviation & Volume (\%) & Biomass (\%) \\
\hline \multirow[t]{7}{*}{ Abies alba } & Stem at $1 \mathrm{~m} 30$ & 8 & 407 & 23 & - & - \\
\hline & Stem w/o knots & 8 & 374 & 16 & 81.1 & 76.1 \\
\hline & Bark & 8 & 514 & 19 & 10.8 & 13.9 \\
\hline & Knots & 8 & 700 & 18 & 0.9 & 1.6 \\
\hline & $\mathrm{Br}$ ins & 8 & 606 & 41 & 0.4 & 0.6 \\
\hline & $\mathrm{Br}$ w/o ins & 8 & 452 & 28 & 6.8 & 7.8 \\
\hline & Aboveground total & & 398 & - & 100.0 & 100.0 \\
\hline \multirow[t]{7}{*}{ Picea abies } & Stem at $1 \mathrm{~m} 30$ & 8 & 356 & 18 & - & - \\
\hline & Stem w/o knots & 8 & 353 & 15 & 82.3 & 77.2 \\
\hline & Bark & 8 & 453 & 48 & 10.2 & 12.3 \\
\hline & Knots & 8 & 682 & 10 & 0.9 & 1.7 \\
\hline & $\mathrm{Br}$ ins & 8 & 630 & 30 & 0.3 & 0.6 \\
\hline & $\mathrm{Br}$ w/o ins & 8 & 497 & 27 & 6.2 & 8.3 \\
\hline & Aboveground total & & 376 & - & 100.0 & 100.0 \\
\hline \multirow{7}{*}{$\begin{array}{l}\text { Pseudotsuga } \\
\text { menziesii }\end{array}$} & Stem at $1 \mathrm{~m} 30$ & 8 & 453 & 47 & - & - \\
\hline & Stem w/o knots & 8 & 429 & 37 & 78.5 & 77.1 \\
\hline & Bark & 8 & 443 & 38 & 11.5 & 11.6 \\
\hline & Knots & 5 & 734 & 25 & 1.2 & 2 \\
\hline & $\mathrm{Br}$ ins & 8 & 588 & 62 & 0.4 & 0.6 \\
\hline & $\mathrm{Br}$ w/o ins & 8 & 450 & 19 & 8.4 & 8.7 \\
\hline & Aboveground total & & 437 & - & 100.0 & 100.0 \\
\hline
\end{tabular}




\section{Appendix 4: Variation of the basic density with the height of the sample in the tree}
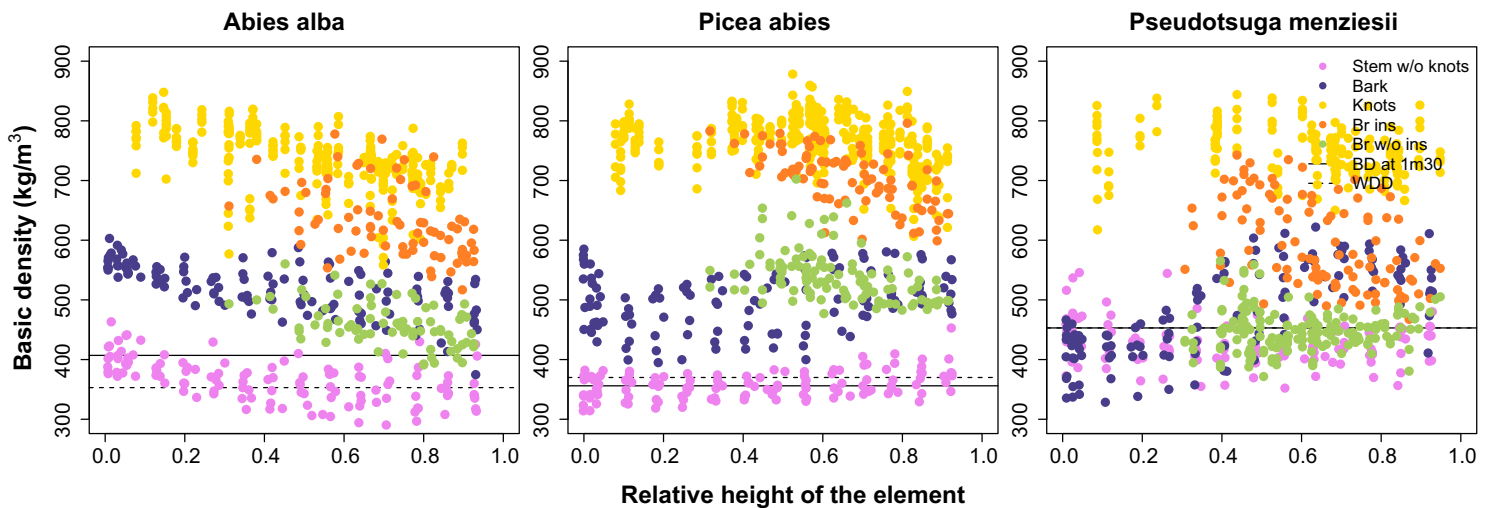

Fig. 8 Basic density versus relative height of each sample for the three

straight line is the mean basic density measured at breast height while species: knot-free stem wood (purple), bark (blue), knots (yellow), the dotted line represents the Global Wood Density Database value

\section{Appendix 5: Pearson's correlation coefficient $r$ between basic density and height of the sample in the tree}

Table 7 Pearson's correlation coefficient $r$ between $B D$ and relative height of each sample for each tree component and each species

\begin{tabular}{|c|c|c|c|c|c|}
\hline Tree species & Stem w/o knots & Bark & Knots & $\mathrm{Br}$ ins & $\mathrm{Br}$ w/o ins \\
\hline \multirow[t]{2}{*}{ Abies alba } & -0.52 & -0.64 & -0.55 & -0.45 & -0.48 \\
\hline & $* * *$ & $* * *$ & $* * *$ & $* * *$ & $* * *$ \\
\hline \multirow[t]{2}{*}{ Picea abies } & 0.36 & 0.24 & -0.28 & -0.62 & -0.42 \\
\hline & $* * *$ & $* *$ & $* * *$ & $* * *$ & $* * *$ \\
\hline \multirow[t]{2}{*}{ Pseudotsuga menziesii } & -0.26 & 0.74 & -0.24 & -0.48 & 0.03 \\
\hline & $* *$ & $* * *$ & $* *$ & $* * *$ & NS \\
\hline
\end{tabular}

The stars indicate the $r$ significance: NS, $p \geq 0.05$ * $^{*}, p<0.05$; **, $p<0.01$; ***, $p<0.001$

that delivered a database for the main French species, TROPIX (Paradis et al. 2015) is a large database constituted by the Centre de coopération internationale en recherche agronomique pour le développement (CIRAD) including many tropical species and that is often used in industry, and the Global Wood Density Database (GWDD) (Zanne et al. 2009a) is an international database compiling a huge number of literature references. The values from TROPIX, that were given for a moisture content of $12 \%$, were converted to basic density (using the usual conversion equation given by Vieilledent et al. (2018)). Note that the GWDD is being corrected due to an error in the conversion formula used in the original publication (Zanne et al. 2009b; Vieilledent et al. 2018) and the corrected database is not available yet. 


\section{Appendix 6: Relationship between mean ring width and basic density at breast height for each species}

Fig. 9 Mean basic density at breast height as a function of mean ring width at breast height for each species (red = Abies alba, blue = Picea abies, beige = Pseudotsuga menziesii) from unthinned plots (circles) and heavily thinned plots (triangles). The $p$ values of the slope are indicated on the graph. The stars indicate the $r$ significance: NS, $p \geq 0.05 ; *, p<0.05 ; * *$, $p<0.01$; ***, $p<0.001$

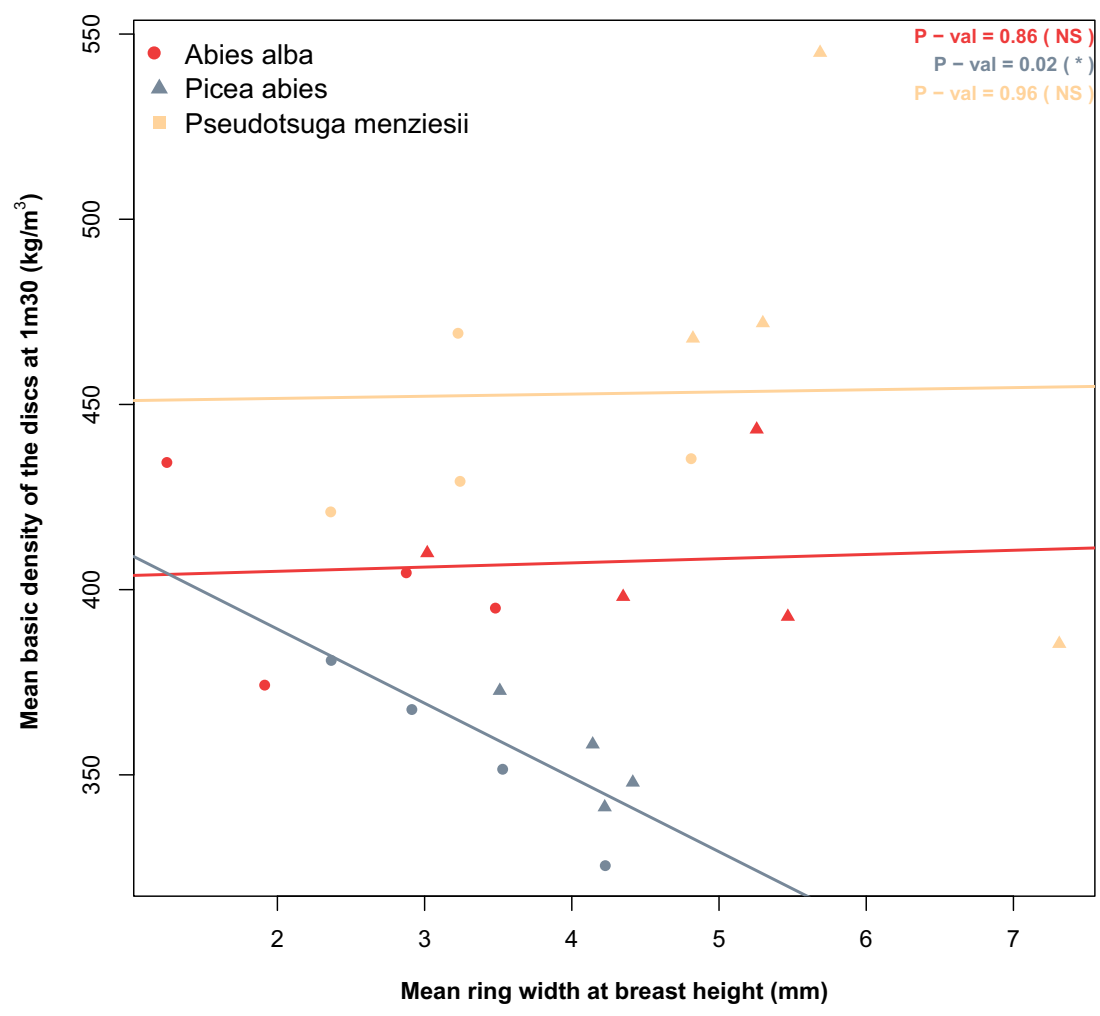

\section{References}

Antonio N, Tomé M, Tomé J, Soares P, Fontes L (2007) Effect of tree, stand, and site variables on the allometry of eucalyptus globulus tree biomass. Can J For Res 37(5):895-906

Bastin JF, Fayolle A, Tarelkin Y, Van den Bulcke J, De Haulleville T, Mortier F, Beeckman H, Van Acker J, Serckx A, Bogaert J, et al. (2015) Wood specific gravity variations and biomass of central African tree species: the simple choice of the outer wood. PloS one 10(11): 0142146

Billard A, Bauer R, Mothe F, Colin F, Longuetaud F (2019) Wood Density variations between tree components should be considered to correctly estimate tree biomass available for different uses. In: NDTE 21st International Nondestructive Testing and Evaluation of Wood Symposium,pp 24-27, September 2019, Freiburg im Breisgau, Germany

Boutelje J (1966) On anatomical structure moisture content density shrinkage and resin content of wood in and around knots in Swedish pine (Pinus Silvestris L) and in Swedish spruce (Picea Abies Karst). Svensk Papperstidning-Nordisk Cellulosa 69(1):1

Bouvet A, Deleuze C (2013) Taux décorce pour les principales essences forestiéres françaises. Rendez-Vous Techniques de l'ONF 39-40:60-67

Brennan M, Fritsch C, Cosgun S, Dumarcay S, Colin F, Gérardin P (2020) Quantitative and qualitative composition of bark polyphenols changes longitudinally with bark maturity in abies alba mill. Ann For Sci 77(1):1-14
Cardoso S, Quilhó T, Pereira H (2019) Influence of cambial age on the bark structure of Douglas-fir. Wood science and technology 53(1):191-210

Colin F, Mothe F, Freyburger C, Morisset JB, Leban JM, Fontaine F (2010) Tracking rameal traces in sessile oak trunks with X-ray computer tomography: biological bases, preliminary results and perspectives. Trees-Structure and Function 24(5):953-967

Corral-Rivas JJ, Vega-Nieva DJ, Rodríguez-Soalleiro R, LópezSánchez CA, Wehenkel C, Vargas-Larreta B, Álvarez-González JG, Ruiz-González AD (2017) Compatible system for predicting total and merchantable stem volume over and under bark, branch volume and whole-tree volume of pine species. Forests 8(11):417

Cown DJ (1967) Densitometric studies on the wood of young coastal Douglas-fir (Pseudotsuga menziesii (Mirb.) Franco). PhD thesis Thesis for the degree of Doctor of Technology, University of British Columbia, Canada

Dibdiakova J, Vadla K (2012) Basic density and moisture content of coniferous branches and wood in northern norway. In: EPJ Web of conferences, EDP sciences, vol 33, p 02005

Enčev E (1962) Obemno teglo: jakost na natisk na drvecinat na klonite na belija bor, smrtša i elata. zusammenfassung: Rohwichte und druckfestigkeit des astholzes der weisskiefer, fichte und tanne. Naučni Trudove 10:177-191

Fearnside PM (1997) Wood density for estimating forest biomass in brazilian amazonia. Forest ecology and management 90(1):59-87

Fegel AC (1941). Comparative anatomy and varying physical properties of trunk, branch, and root wood in certain northeastern trees. Cited by Gartner (1995) 
Filbakk T, Jirjis R, Nurmi J (2011) The effect of bark content on quality parameters of scots pine (pinus sylvestris 1.) pellets. Biomass and Bioenergy 35(8):3342-3349

Franceschini T, Longuetaud F, Bontemps JD, Bouriaud O, Caritey BD, Leban JM (2013) Effect of ring width, cambial age, and climatic variables on the within-ring wood density profile of Norway spruce picea abies (1.) karst. Trees 27(4):913-925

Freyburger C, Longuetaud F, Mothe F, Constant T, Leban JM (2009) Measuring wood density by means of X-ray computer tomography. Ann For Sci 66(8):804

Gartner BL (1995) Patterns of xylem variation within a tree and their hydraulic and mechanical consequences. In: Plant Stems, Elsevier, pp 125-149

Gómez-García E, Biging G, García-Villabrille JD, Crecente-Campo F, Castedo-Dorado F, Rojo-Alboreca A (2015) Cumulative continuous predictions for bole and aboveground woody biomass in eucalyptus globulus plantations in northwestern spain. Biomass and bioenergy 77:155-164

Gryc V, Horáček P, Šlezingerová J, Vavrčík H et al (2011) Basic density of spruce wood, wood with bark and bark of branches in locations in the czech republic. Wood research 56(1):14-23

Hakkila P (1971) Coniferous branches as a raw material source. Communicationes Institute Forestalis Fenniae, 75(1) p 1-51

Holmbom B, Eckerman C, Eklund P, Hemming J, Nisula L, Reunanen M, Sjöholm R, Sundberg A, Sundberg K, Willför S (2003) Knots in trees-a new rich source of lignans. Phytochem Rev 2(3):331-340

IPCC (2006) Guidelines for national greenhouse gas inventories. Technical report. Prepared by the National Greenhouse Gas Inventories Programme. The Intergovernmental Panel on Climate Change IPCC/IGES, Kanagawa, Japan

Kebbi-Benkeder Z, Colin F, Dumarçay S, Gérardin P (2015) Quantification and characterization of knotwood extractives of 12 European softwood and hardwood species. Ann For Sci 72(2):277-284

Kebbi-Benkeder Z, Dumarçay S, Touahri N, Manso R, Gérardin P, Colin F (2016) Les noeuds: un bois méconnu et une source importante de composés extractibles. Revue Forestiére Française 68:7-26

Kebbi-Benkeder Z, Manso R, Gérardin P, Dumarçay S, Chopard B, Colin F (2017) Knot extractives: a model for analysing the ecophysiological factors that control the within and between-tree variability. Trees 31(5):1619-1633

Koga S, Zhang S (2004) Inter-tree and intra-tree variations in ring width and wood density components in balsam fir (abies balsamea). Wood Sci Technol 38(2):149-162

Lachenbruch B, Moore JR, Evans R (2011) Radial variation in wood structure and function in woody plants, and hypotheses for its occurrence. In: Size-and age-related changes in tree structure and function, Springer, pp 121-164

Lehtonen I (1978) Knots in scots pine (Pinus sylvestris L.) and Norway spruce (Picea abies (L.) Karst.) and their effect on the basic density of stemwood. Communicationes Instituti Forestalis Fenniae 95:1-34

Longuetaud F, Santenoise P, Mothe F, Kiessé TS, Rivoire M, SaintAndré L, Ognouabi N, Deleuze C (2013) Modeling volume expansion factors for temperate tree species in France. For Ecol Manag 292:111-121

Longuetaud F, Mothe F, Fournier M, Dlouha J, Santenoise P, Deleuze C (2016) Within-stem maps of wood density and water content for characterization of species: a case study on three hardwood and two softwood species. Ann For Sci 73(3):601-614

Longuetaud F, Mothe F, Fournier M, Dlouha J, Santenoise P, Deleuze C (2017) Patterns of within-stem variations in wood specific gravity and water content for five temperate tree species. Ann For Sci 74(3):64
Loustau D (2004) Rapport final du projet carbofor : Séquestration de carbone dans les grands écosystémes forestiers en france. quantification, spatialisation, vulnérabilité et impacts des différents scénarios climatiques et sylvicoles. bordeaux. http://www. gip-ecofor.org/gicc/?p=592

McKimmy MD, Ching KK (1968) Correlating specific gravities of branch and bole wood in young Douglas fir. Forest Res. Lab Report G-8, Oregon State Univ, Corvallis

Miles PD, Smith WB (2009) Specific gravity and other properties of wood and bark for 156 tree species found in North America, vol 38 US Department of Agriculture, Forest Service, Northern Research Station

Nogueira EM, Fearnside PM, Nelson BW (2008) Normalization of wood density in biomass estimates of Amazon forests. For Ecol Manag 256(5):990-996

Norin T, Winell B (1972) Extractives from the bark of common spruce, picea abies 1. karst. Acta Chemica Scandaniva 26:2289-2296

Patel RN (1975) Bark anatomy of radiata pine, corsican pine, and douglas fir grown in new zealand. New Zealand journal of botany 13(2):149-167

Petráš R, Mecko J, Krupova D, Slamka M, Pažitný A (2019) Aboveground biomass basic density of softwoods tree species. Wood Research 2(64):205-212

Polge H (1966) Établissement des courbes de variation de la densité du bois par exploration densitométrique de radiographies d'échantillons prélevés á la tariére sur des arbres vivants: applications dans les domaines technologique et physiologique. Annales des Sciences forestiéres 23(1):I-206

Paradis S, Guibal D, Gérard J, Beauchêne J, Brancheriau L, Cabantous B, Châlon I, Daigremont C, Détienne P, Fouquet D, et al. (2015) Tropix 7.5. 1: caractéristiques technologiques de 245 essences tropicales et tempérées. https://tropix.cirad.fr/

Pretzsch H (2009) Forest dynamics, growth, and yield. In: Forest dynamics, growth and yield, Springer, pp 1-39

R Core Team (2018) R: A Language and Environment for Statistical Computing. R Foundation for Statistical Computing, Vienna. https://www.R-project.org/

Repola J (2006) Models for vertical wood density of Scots pine, Norway spruce and birch stems, and their application to determine average wood density. Silva Fennica 40(4):673-685

Rothpfeffer C, Karltun E (2007) Inorganic elements in tree compartments of picea abiesconcentrations versus stem diameter in wood and bark and concentrations in needles and branches. Biomass Bioenergy 31(10):717-725

Sagang LBT, Takoudjou Momo S, Bakonck Libalah M, Rossi V, Fonton N, Mofack GI, Kamdem NG, Nguetsop VF, Sonké B, Ploton P, Barbier N, et al. (2018) Using volume-weighted average wood specific gravity of trees reduces bias in aboveground biomass predictions from forest volume data. Forest ecology and management 424:519-528

Schneider CA, Rasband WS, Eliceiri KW (2012) NIH Image to imagej: 25 years of image analysis. Nat Methods 9(7):671

Somogyi Z, Cienciala E, Mäkipää R, Muukkonen P, Lehtonen A, Weiss P (2007) Indirect methods of large-scale forest biomass estimation. Eur J For Res 126(2):197-207

Spicer R, Gartner BL (1998) Hydraulic properties of Douglasfir (Pseudotsuga menziesii) branches and branch halves with reference to compression wood. Tree Physiology 18(11):777784

Stovall AE, Vorster AG, Anderson RS, Evangelista PH, Shugart $\mathrm{HH}$ (2017) Non-destructive aboveground biomass estimation of coniferous trees using terrestrial lidar. Remote Sens Environ 200:31-42

Vashum KT, Jayakumar S (2012) Methods to estimate above-ground biomass and carbon stock in natural forests-a review. Journal of Ecosystem \& Ecography 2(4):1-7 
Vieilledent G, Fischer FJ, Chave J, Guibal D, Langbour P, Gérard J (2018) New formula and conversion factor to compute basic wood density of tree species using a global wood technology database. American journal of botany 105:1653-1661

Wassenberg M, Chiu HS, Guo W, Spiecker H (2015) Analysis of wood density profiles of tree stems: incorporating vertical variations to optimize wood sampling strategies for density and biomass estimations. Trees 29(2):551-561

Wegelius T (1940) The presence and properties of knots in Finnish spruce: investigations concerning the origin and characteristics of branch and knot wood in Finnish spruce with particular consideration given to the raw material needs of the paper industry., vol 48. Acta Forestalia Fennica

Wei Q, Leblon B, La Rocque A (2011) On the use of X-ray computed tomography for determining wood properties: a review. Can J For Res 41(11):2120-2140

Wiemann MC, Williamson GB (2013) Biomass determination using wood specific gravity from increment cores. USDA Forest Service, Forest Products Laboratory, General Technical Report, FPL-GTR-225 225:1-9
Wiemann MC, Williamson GB (2014) Wood specific gravity variation with height and its implications for biomass estimation. USDA Forest Service, Forest Products Laboratory, Res Pap 677:1-12

Williamson GB, Wiemann MC (2010) Measuring wood specific gravity correctly. Am J Bot 97(3):519-524

Zhu K, Zhang J, Niu S, Chu C, Luo Y (2018) Limits to growth of forest biomass carbon sink under climate change. Nature communications 9(1):2709

Zanne AE, Lopez-Gonzalez G, Coomes DA, Ilic J, Jansen S, Lewis SL, Miller RB, Swenson NG, Wiemann MC, Chave J (2009) Data from: Towards a worldwide wood economics spectrum. dryad digital repository. https://datadryad.org/stash/dataset/doi:10.5061/ dryad.234

Zanne AE, Lopez-Gonzalez G, Coomes DA, Ilic J, Jansen S, Lewis SL, Miller RB, Swenson NG, Wiemann MC, Chave J (2009) Global wood density database

Publisher's note Springer Nature remains neutral with regard to jurisdictional claims in published maps and institutional affiliations.

\section{Affiliations}

\section{Antoine Billard $^{1}$ (D) . Rodolphe Bauer ${ }^{1}$ - Frédéric Mothe ${ }^{1} \cdot$ Mathieu Jonard $^{2} \cdot$ Francis Colin $^{1}$ • Fleur Longuetaud ${ }^{1}$}

Rodolphe Bauer

rodolphe.bauer@inrae.fr

Frédéric Mothe

frederic.mothe@inrae.fr

Mathieu Jonard

mathieu.jonard@uclouvain.be

Francis Colin

francis.colin@inrae.fr

Fleur Longuetaud

fleur.longuetaud@inrae.fr

1 AgroParisTech, INRAE, Silva, Université de Lorraine, 54000 Nancy, France

2 UCL-ELI, Earth and Life Institute, Environmental Sciences, Université Catholique de Louvain, Croix du Sud, 2 - box L7.05.09,

B-1348 Louvain-la-Neuve, Belgium 